\title{
Organizational culture and innovation the case of Workers Sports Federations artworks Qatar
} Dr. Ahmed Abdul rahman AL-Emadi

\section{Innovation}

Given that the locus of this study is innovation, the concept needs to be defined as a first step. Innovation is "a process of developing and implementing a new idea [it] refers to the process of bringing any new problem solving idea into use ... it is the generation, acceptance, and implementation of new ideas, processes, products, or services" (Van deVen \& Angle, 1989, p. 12). In the words of McLean (2005), innovation is the process by which these ideas are captured, filtered, funded, developed, modified, clarified, and eventually commercialized and/or implemented. As can be discerned from these definitions, words associated with innovation include creativity, idea, invention, and breakthrough. Innovation is about "a process of developing and implementing a new idea" (Van deVen \& Angle, 1989, p. 12). It is the successful implementation of new, creative ideas within an organization it then follows that no innovation is possible without identifying problems and opportunities, gathering information, generating new ideas, and exploring the validity of those ideas" (Amabile, 2004, p. 1).

It is unfortunate that there has been relatively little empirical work done in the area of organizational culture and innovation (Amabile, 1998), especially considering how important innovation is in any organization. With specific relevance to the present research, the existing literature investigating the relationship between organizational culture and innovation is very limited (McLean, 2005).

\section{Research problem}

Overall, research in sport management is characterized as being relatively lacking (Andrew at al., 2011). Research connected with aspects of organizational culture is no different. For, with specific reference to the area of organizational culture and performance, research is still in its infancy. 
Certain applied research studies confirm that there are different levels of performance between sports federations and link these different performance levels primarily to differences in the organizational cultures of these federations and the rules or norms they enforce (5: 5). In addition, the sports federations lack the spirit of innovations, which is a principal driver of growth and improvement in modern administration. For it is no longer sufficient for an organization to espouse a traditional approach in functioning and furnishing products or delivering services. Because the outcome of an approach such as this would be the failure of the organization, innovation and creativity must be the fundamental characteristics of any organization of this kind.

The significance of the study lies in the emphasis it places on the impact which organizational culture that is current in sports federations in the State of Qatar has on performance levels. Hence, the study seeks to decipher the degree of correlation between success or failure of sports federations and the type of organizational culture embraced in these federations. Similarly, the choice of sports federations in Qatar to undertake the present research and explore the effect of organizational culture on innovative abilities is an important step given that the State of Qatar is the country that continues to organize most of the sports games in the Middle East.

Examining the nature of the relationship between organizational culture and the capacity for innovation may be indicative of (a) the positive role they play in the successful cases of certain federations or (b) their negative role in cases of these federations' failure. This study also tries to investigate how the role of organizational culture may be promoted, if positive, and how it can be redressed to become more effective, if it has a negative role.

\section{Previous studies}

Yun Seok Choi's study (2005) sought to identify patterns and types of organizational culture based on a sample of baseball organizations in the USA and Korea. The researcher employed the survey method 
using

questionnaires

administered to a sample of employees working at highly performing clubs. The main findings of this study revealed that a significant difference existed in the cultural strength of four cultural types based on three variables: size, winning percentage and attendance level.

Kristina Jaskyte's study (2005) is an exploratory examination of the correlation between organizational culture and organizational innovation in non-profit organizations. The researcher employed a descriptive, cross-sectional survey based on a convenience sampling methodology in collecting the data from a sample of non-profit organizations. Organizational innovation was found to be a significant predictor of organizational performance in non-profit organizations.

The aim of Joseph Kevin Valadares's study (2005) was to identify the relationship between organizational culture and its ability to empower health care ethics. Using personal interviews and survey questionnaires, the research conducted an experimental study implemented on a sample of health care employees. The study identified a direct positive relationship between organizational culture and organizational ethics.

A study conducted by Samia Farid Mohamed (2006) explored the role of organizational culture in empowering personnel and its impact on the success of Egyptian basketball federation. Using a descriptive method, researcher implemented personal interviews and survey questionnaires to gather data from a sample of Egyptian basketball federation employees. The results revealed lack of interest in the level of education of job applicants and the absence of incentives for outstanding candidates.

The purpose of Manal Ismail Mohamed's study (2007) was to identify the impact of organizational culture, degree of job satisfaction, and personal traits on the manager's innovative ability. Using a descriptive study, the researcher administered cross-sectional questionnaires to a sample of middle class, food and beverage managers. The results yielded a statistically 
significant, positive correlation between organizational culture and innovative abilities.

Iman

Saber

Abdulrahmane's study (2008) investigated the relationship between organizational culture and organizational development regarding the management of sports activities in Alexandria major/biggest clubs. The study involved interviews and questionnaires applied on a sample of middle and upper level, and executive club management. Organizational culture was found to contribute to paying attention to the needs of individuals and to promote externally- and internallyfocused communication.

\section{Review of the studies above}

The studies referred to above tackled different aspects of organizational culture, including innovative abilities and the relationships between organizational culture and innovation. In the present study, the researcher further explored this relationship and utilized a descriptive methodology, hence the use of the questionnaire instrument in collecting the data needed for this research. The previous studies also differ in terms of the sample types chosen and the manner in which they were chosen. This provided insights for the research and illuminated his decision to implement his study on sports federations in Qatar.

\section{Research objective}

The main goal of the research presented in this paper was to investigate the relationship between organizational culture and the innovative abilities of certain sports federations in Qatar. This goal would be attained in a number of ways:

1. Ascertaining the relationship between organizational culture and the innovative abilities of sports federations employees in Qatar;

2. Establishing a basis for common aspects of organizational culture in sports federations in Qatar through examining the characteristics of organizational cultures of Qatari sports federations;

3. Determining the type of organization culture characterizing sports federations in Qatar, especially the types that pertain to planning and control, etc.

Research questions 
- Is there a relationship between organizational culture and innovative ability with regard to the type of sport federation in Qatar?

- Is there a relationship between organizational culture and innovative ability with regard to the type of position occupied (administrator, technician) at the sport federation?

- Is there a relationship between organizational culture and innovative ability with regard to the employee's years of experience at the sport federation in Qatar?

\section{Research procedures}

\section{Research methodology}

In order to gather the data needed for this study, descriptive survey research was employed. The methodology used utilizes quantitative tools in collecting and analyzing the data.

\section{Research population}

The population involved in this research comprised administrators, employees and members of the following sports federations in Qatar for the 2010-2011 season: Athletics Federation, Swimming Federation, Tennis Federation, Football Federation, Handball Federation, and Volleyball Federation.

\section{Research sample}

The population needed for this survey research comprised all employees at the six sports federations in Qatar. The research population comprised 120 people, 20 of whom were chosen as a sample for the survey. Hence, the population selected for the main study consisted of 100 people and the response rate was $80 \%$ of the population involved in the research, i.e. 80 respondents. Table 1 demonstrates the distribution of the participants according to the category of sport federation.

\section{Table (1)}

Sample distribution by federation $(\mathbf{n}=80)$

\begin{tabular}{c|c|c|c}
\hline \hline & Federation & Number & \% \\
\hline \hline 1 & Athletics & 10 & 12.5 \\
\hline 2 & Swimming & 10 & 12.5 \\
\hline 3 & Handball & 11 & 13.8 \\
\hline 4 & Football & 11 & 13.8 \\
\hline 5 & Volleyball & 20 & 25 \\
\hline 6 & Tennis & 18 & 22.5 \\
\hline \hline
\end{tabular}

Assiut Journal For Sport Science Arts 


\section{Data}

collection

instruments

To collect the data required for this study, the researcher utilized questionnaires.

2. Implementation stages Research procedures

\section{a) Designing}

the

\section{questionnaires}

The questionnaires designed for this investigation were informed by insights from the relevant literature. For instance, a questionnaire on organizational culture and its relationship to innovative abilities in some sports federations in Egypt illuminated the questionnaire used in the research. Hence, invaluable inspirations emanated from the works of prominent scholars and researchers (2).

Changes were made to this questionnaire as deemed appropriate for this study of sports federations in Qatar. Accordingly, the questionnaire was divided into two parts. The first part focuses on organizational culture and its relationship to innovative abilities in sports federations while the second deals with the measurement of the characteristics of innovation. b) Validity and reliability of the questionnaire

Validity of the questionnaire

To elicit information about the research topic and determine the validity of the questionnaire instrument, the researcher resorted to the following procedures:

- Internal consistency between the statements comprised under each of the four themes used in the questionnaire and the questionnaire in its totality,

- Internal consistency between the four themes and the overall questionnaire as a whole

- Internal consistency with regard to the questionnaire on innovative abilities, which encompassed 12 themes, through calculating the correlation coefficient. The calculated (r) value for the overall questionnaire themes fell between 0.91-0.99 and the tabulated $(\underline{r})$ value was $0.05=$ 0.44 , which is statistically acceptable. This confirms the validity of the statements included under the relevant themes.

Reliability of the questionnaire (test \& re-test)

- As a first step in collecting research data and in 
order to verify the validity of the organizational culture questionnaire, the researcher relied on two application phases; the test was carried out prior to the re-test (Andrew at al., 2011). This allows testing the quality of the data and the data collection procedure. It ensures that the data gathered is valid and reliable and that the research instrument is adequate for the task it is designed for. In addition, testing and re-testing the questionnaires allows identifying problems and difficulties that might hamper the understanding of instructions or the questions. The first and second implementation phases of the questionnaire revealed a large degree of similarity; both rounds involved a sample composed of 20 , with a twoweek interval between the first and second applications. The mean for the test responses regarding the questionnaire themes as a whole was $149.42 \%$ with a computed standard deviation of 22.76 . The mean for the re-test round responses was $142.37 \%$, with a computed standard deviation of 35.38. The observed ( $r$ ) value between the two applications was $0.98 \%$, hence augmenting the trustworthiness of the questionnaire themes.

- The researcher also calculated the validity of the questionnaire focusing on innovative abilities through two implementation rounds on a sample composed of 20 participants with an interval of two weeks. The mean for the response rate corresponding to the questionnaire themes was $87.70 \%$ and the standard deviation was 23.28. In contrast, the mean for the responses regarding the re-test round was $85.00 \%$, the standard deviation computed at $25.50 \%$, and an (r) value for the two applications calculated at $0.89 \%$, enhances the credibility and trustworthiness of the questionnaire themes, hence increasing its reliability. 
Table (2)

Results and discussion The percentages for the participants' satisfaction with organizational culture $(n=80)$

\begin{tabular}{l|c|c}
\hline \multicolumn{1}{c|}{ Theme } & $\begin{array}{c}\text { Estimated } \\
\text { score }\end{array}$ & $\%$ \\
\hline $\begin{array}{l}\text { Theme 1: Team work and } \\
\text { participation }\end{array}$ & 3351 & 69.81 \\
\hline $\begin{array}{l}\text { Theme 2: Maintaining agreement and } \\
\text { harmony }\end{array}$ & 3416 & 71.17 \\
\hline Theme 3: Innovation culture & 3882 & 68.11 \\
\hline $\begin{array}{l}\text { Theme 4: Ability of the federations' } \\
\text { employees to collaborate with other } \\
\text { federations }\end{array}$ & 804 & 67.00 \\
\hline The overall questionnaire & 11453 & 69.41 \\
\hline \hline
\end{tabular}

Table 2 above demonstrates that $69.41 \%$ of the participants who responded to all different themes of the questionnaire enjoy a good organizational culture. The second theme, namely the ability to maintain agreement and harmony came in the first rank, i.e. $71.17 \%$ of the participants' responses. The first theme, i.e. Team work and participation, ranked second, i.e. $69.81 \%$ of the participants' responses. Innovation culture, the third theme, occupied the third position $(68.11 \%)$ whereas the fourth theme, i.e. the ability of the federations' employees to collaborate with other federations, ranked last $(67.00 \%)$.

The analysis of the participants' responses yielded results that appear to be logical for two main reasons. The first is the fluidity which characterizes the organizational structure of the sports institutions in Qatar; the second is related to the logical distribution of roles and areas of specialization, distributed equally between leaders and authorities on the basis of the values of delegating tasks and responsibilities, as well as rationalizing decisions. A characteristic of these organizations concerns the preference of limited levels of supervision. This type of culture operates in stable environments characterized by a great degree of consistency and cohesion among employees in the different Assiut Journal For Sport Science Arts 
sports sectors, and this facilitates a great amount of flexibility in making and executing decisions. Undoubtedly, this has had a positive impact on Qatar's ability to host and organize many regional and international competitions, including the spectacular organization of Asian Games in 2006 as well as the preparation of Qatar's bid to host the 2022 World Cup, which stunned the world and led to earning the first place and hence winning over many powerful countries. Indeed, this provides clear evidence of the high quality of organizational culture that administrative and supervisory bodies have, which may in turn exceed the responses of the participants in this study.

Table (3)

Percentage for participants' satisfaction with innovative abilities $(\mathbf{n}=80)$

\begin{tabular}{c|l|c|c}
\hline \hline & Theme & $\begin{array}{c}\text { Estimated } \\
\text { score }\end{array}$ & \% \\
\hline \hline 1 & Theme 1: Fluency & 823 & 68.58 \\
\hline 2 & Theme 2: Flexibility & 829 & 69.08 \\
\hline 3 & Theme 3: Authenticity & 655 & 72.78 \\
\hline 4 & Theme 4: Imagination & 829 & 69.08 \\
\hline 5 & Theme 5: Internal motivation & 590 & 65.56 \\
\hline 6 & Theme 6: Sensitivity to problems & 402 & 67.00 \\
\hline 7 & Theme 7: Love of risk-taking & 672 & 56.00 \\
\hline 8 & Theme 8: Self-confidence & 643 & 71.44 \\
\hline 9 & Theme 9: Positive attitudes & 627 & 69.67 \\
\hline 10 & Theme 10: Persistence & 881 & 73.42 \\
\hline 11 & Theme 11: Tendency to develop & 338 & 56.33 \\
\hline 12 & The questionnaire as a whole & 7289 & 67.49 \\
\hline \hline
\end{tabular}

As is clear from Table 3 above, $67.49 \%$ of the participants possess good innovative abilities, as is manifest in the responses they provided with regard to the questionnaire items in general.
For instance, theme 10 (persistence) ranked first among the participants' responses (i.e. $73.42 \%$ ), followed by theme 3 (authenticity) in the second position with $72.78 \%$. Theme 
8 , Self-confidence, came in the third position (i.e. 71.44\%) while theme 9 (positive attitudes) occupied the fourth position $(69.67 \%)$. In contrast, flexibility and imagination came in the fifth position (68.08\%), respectively, followed by theme 1 (fluency) in the sixth position (68.58\%). Theme six (sensitivity to problems) ranked seventh, i.e. $67.00 \%$, while theme seven (Love of risk-taking) came in the eighth position (56.00\%). Theme five, i.e. internal motivation occupied the ninth position $(56.56 \%)$ and theme 11 , i.e. tendency to develop, came in the last position $(56.33 \%)$.

Based on the analysis of the responses of this study's participants, it is clear that the administrative apparatuses in the sports organizations in Qatar enjoy a great degree of innovation, the main components of which encompass: innovation, generation and execution of new ideas and rendering them in concrete form. Determination, persistence, original thought, and selfconfidence are dominant features of the administrative system of sports organizations in Qatar. This is reflected in Qatar's bid to host the 2022 World Cup, an honor that Qatar won deservedly owing to the innovative and valuable ideas the bid brought about. Examples of these ideas include solutions to the sizzling summer heat and adherence to the authentic style of architecture in the design of football stadiums. These ideas also provide testimony to the original, authentic Arab Qatari culture as well as unprecedented solutions that will aid in overcoming problems associated with hosting an event of such magnitude as the World Cup.

Table (4)

One-Way Analysis of Variance for sports federations organizational culture $(n=80)$

\begin{tabular}{|c|c|c|c|c|c|c|c|}
\hline & Variables & $\begin{array}{c}\text { Source } \\
\text { of } \\
\text { variance }\end{array}$ & $\begin{array}{c}\text { Degree } \\
\text { of } \\
\text { freedom }\end{array}$ & $\begin{array}{l}\text { Sum of } \\
\text { squares }\end{array}$ & $\begin{array}{c}\text { Mean } \\
\text { squares }\end{array}$ & $\begin{array}{c}\text { Value } \\
\text { (f) }\end{array}$ & Significance \\
\hline \multirow{2}{*}{1} & \multirow[t]{2}{*}{$\begin{array}{l}\text { Organizational } \\
\text { culture }\end{array}$} & $\begin{array}{l}\text { Inter- } \\
\text { group }\end{array}$ & $\overline{5}$ & YqTV.0. & 094.0. & \multirow[t]{2}{*}{2.20} & \multirow[t]{2}{*}{ Insignificant } \\
\hline & & $\begin{array}{l}\text { Intra- } \\
\text { group }\end{array}$ & 74 & $199 \vee 9.49$ & 179.99 & & \\
\hline
\end{tabular}

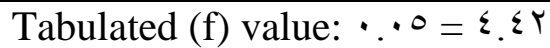

Assiut Journal For Sport Science Arts 
As noted in Table 4, no significant differences were observed between the different sports federations in Qatar, with respect to organizational culture; for the computed between-group mean score was 595.50 whereas the withingroup mean score was 269.99. The Tabulated (f) value was 2.20 , calculated at 0.05 , which is lower than the estimated tabulated value of $4.42(\%)$. It may be argued that these results came as no surprise, owing to the good organizational structure characterizing administrative federations. sports organizations in Qatar, in addition to the logical distribution of roles and areas of specialization, distributed equally between leaders and authorities on the basis of the values of delegating tasks and responsibilities, as well as rationalizing decisions. This $\underline{\text { is }}$ the reason sports federations operate according to a unified leadership and administration organization, hence showing no inherent or fundamental differences in the administrative and organizational systems of the sports

Table (5)

One-Way Analysis of Variance for sports federations innovative abilities $(\mathbf{n}=\mathbf{8 0})$

\begin{tabular}{l|l|l|l|l|l|l|l}
\hline \hline ??? & Variables & $\begin{array}{l}\text { Source } \\
\text { of } \\
\text { variance }\end{array}$ & $\begin{array}{l}\text { Degree } \\
\text { of } \\
\text { freedom }\end{array}$ & $\begin{array}{l}\text { Sum of } \\
\text { squares }\end{array}$ & $\begin{array}{l}\text { Mean } \\
\text { squares }\end{array}$ & $\begin{array}{l}\text { Value } \\
\text { (f) }\end{array}$ & Significance \\
\hline \hline \multirow{2}{*}{$\mathbf{1}$} & \multirow{2}{*}{$\begin{array}{l}\text { Innovative } \\
\text { abilities }\end{array}$} & $\begin{array}{l}\text { Inter- } \\
\text { group }\end{array}$ & 5 & 3865.12 & 773.02 & 4.50 & Significant \\
\cline { 3 - 5 } & & $\begin{array}{l}\text { Intra- } \\
\text { group }\end{array}$ & 74 & 12711.88 & 171.78 & & \\
\hline \hline
\end{tabular}

Tabulated (f) value: $\cdot \cdot^{\cdot 0}=\varepsilon$. $\{$ r

As can be seen from Table 5 above, significant differences were observed between the sports federations in Qatar, with respect to innovative abilities. The calculated between-group mean score was 773.02 and the within-group mean score was 171.78. The Tabulated (f) value was 4.50 , computed at 0.05 , which is higher than the estimated tabulated value of $4.42(\%)$. It could be argued 
that these results were not surprising, because individual games are characterized by greater fluency, flexibility, tendency to develop, creativity, innovation through new, unprecedented solutions to problems, something that is lacking in group games.

Table $(6$

Significance of difference in mean scores for sports federation using L.S.D test, with respect to innovative abilities $(n=80)$

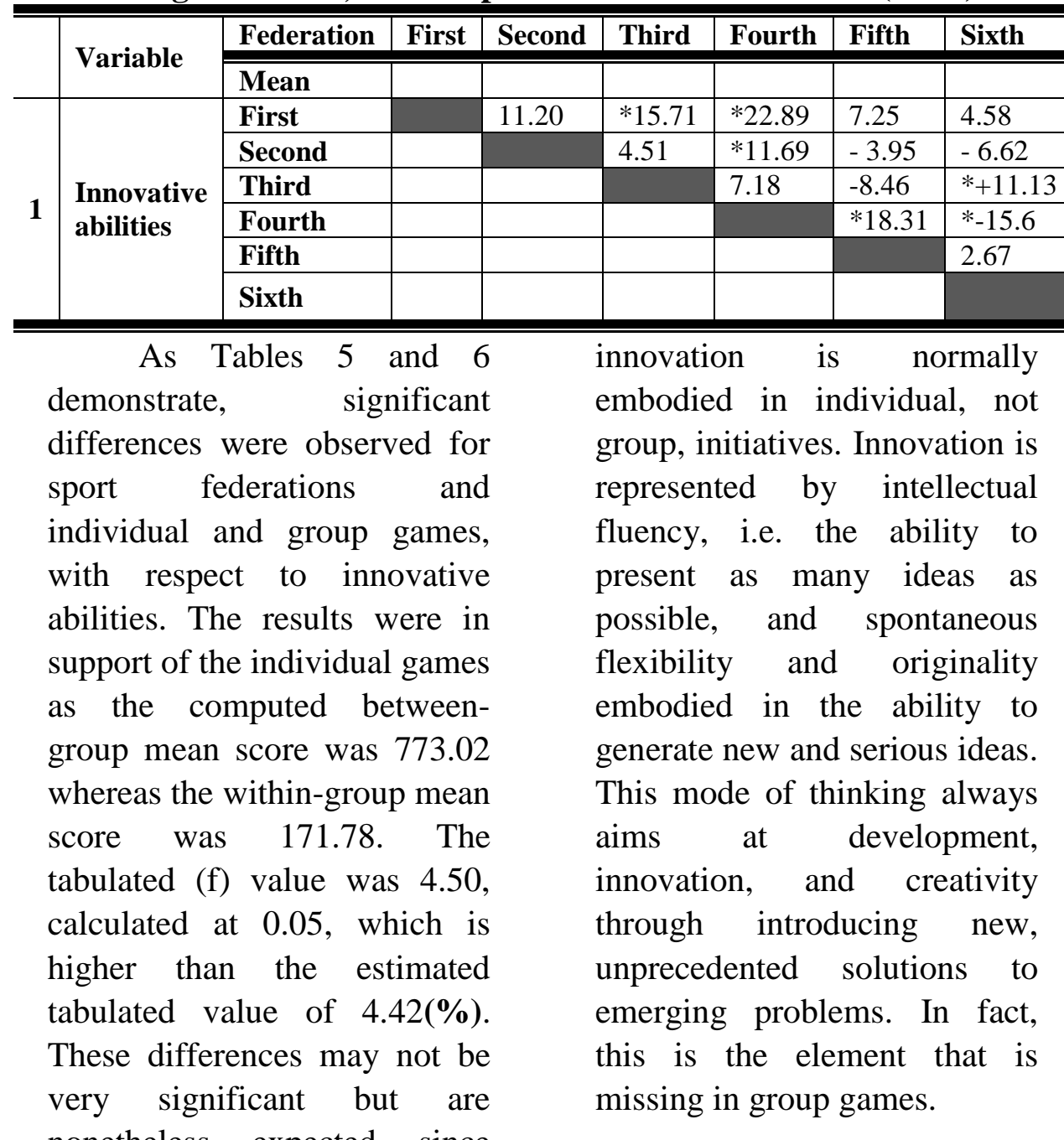
nonetheless expected since 
Table (7)

Correlation coefficient between organizational culture \& innovative abilities according to sport federation $(n=80)$

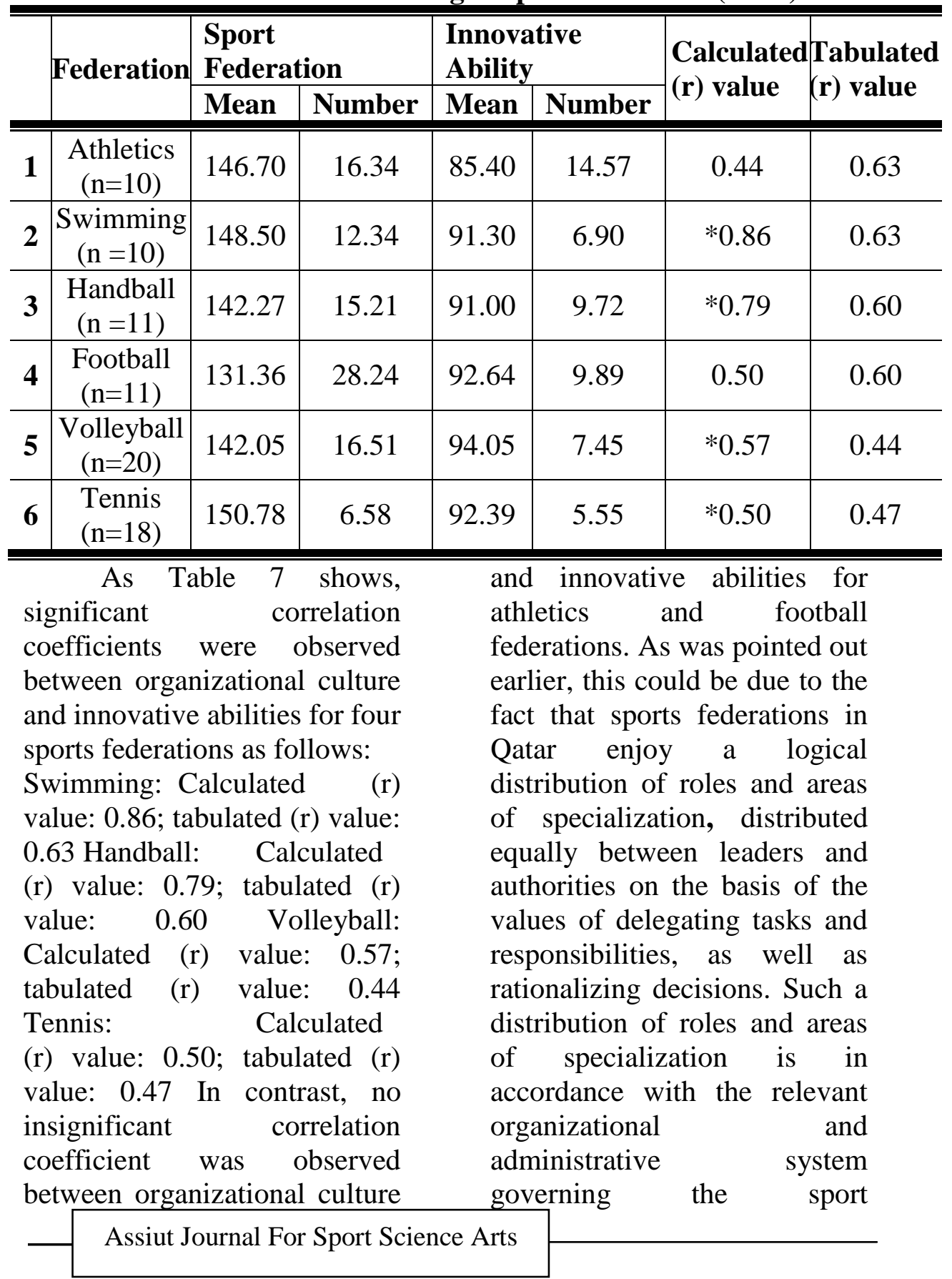


organization, which yields a great degree of organization, flexibility, and fluency which are all essential components of innovation.

\section{Table (8)}

Correlation coefficient between organizational culture $\&$ innovative abilities according to the nature of work $(n=80)$

\begin{tabular}{l|l|l|l|l|l|l|l}
\hline \hline \multirow{2}{*}{ Federation } & \multicolumn{2}{l}{$\begin{array}{l}\text { Organizational } \\
\text { Culture }\end{array}$} & \multicolumn{2}{l|}{$\begin{array}{l}\text { Innovative } \\
\text { Abilities }\end{array}$} & \multirow{2}{*}{$\begin{array}{l}\text { Calculated } \\
\text { (r) value }\end{array}$} & $\begin{array}{l}\text { Tabulated } \\
\text { (r) value }\end{array}$ \\
\cline { 3 - 6 } & & Mean & No & Mean & No & & \\
\hline \hline $\mathbf{1}$ & Administrative & 141.16 & 18.27 & 91.31 & 8.32 & $* 0.53$ & 0.29 \\
\hline $\mathbf{2}$ & Technical & 147.57 & 14.80 & 92.06 & 9.88 & $* 0.37$ & 0.33 \\
\hline \hline
\end{tabular}

As is clear from Table 8 above, significant correlation coefficients were observed between organizational culture and innovative abilities, with respect to the type of work (administrative or technical). Thus, the calculated and tabulated values revealed that

Table (9)

Correlation coefficient between organizational culture $\&$ innovative abilities according to years of experience $(n=80)$

\begin{tabular}{|c|c|c|c|c|c|c|c|}
\hline & \multirow{2}{*}{$\begin{array}{l}\text { Years of } \\
\text { Experience }\end{array}$} & \multicolumn{2}{|c|}{$\begin{array}{l}\text { Organizational } \\
\text { Culture }\end{array}$} & \multicolumn{2}{|c|}{$\begin{array}{l}\text { Innovative } \\
\text { Abilities }\end{array}$} & \multirow{2}{*}{$\begin{array}{l}\text { Calculated } \\
\text { (r) value }\end{array}$} & \multirow{2}{*}{$\begin{array}{l}\text { Tabulated } \\
\text { (r) value }\end{array}$} \\
\hline & & Mean & No & Mean & No & & \\
\hline 1 & \begin{tabular}{|lrr}
$\begin{array}{l}1 \\
(n=23)\end{array}$ & 10 \\
\end{tabular} & $1 \leq \leqslant .9$ & $11.9 \mathrm{~V}$ & QY.Ar & $\overline{\nu . r .}$ & $* . . V \leq$ & $\cdot \Omega 1$ \\
\hline 2 & $\begin{array}{lr}11 \text { to } 20 \\
(\mathrm{n}=26)\end{array}$ & $1 \leq Y .$. & $1 \Lambda . V Y$ & $q Y \leq Y$ & 0.94 & $\because V$ & $\cdot .49$ \\
\hline 3 & 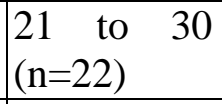 & $1 \leqslant \Lambda .1 \leqslant$ & $1 Y .00$ & 9Y.YT & 9.19 & $* . . \vee \wedge$ & $\cdot \leqslant r$ \\
\hline 4 & $\begin{array}{l}31 \text { to } 40 \\
(\mathrm{n}=9)\end{array}$ & 119.11 & $17 . \wedge \varepsilon$ & $1 \leqslant .07$ & $10.9 \mathrm{~V}$ & 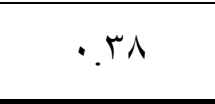 & $.7 \mathrm{~V}$ \\
\hline
\end{tabular}

The results presented in Table 9 above show that significant for Administrative jobs, the Calculated (r) value was 0.53 whereas the tabulated $(r)$ value was 0.29. For Technical jobs, on the other hand, the Calculated (r) value was 0.37 and the tabulated (r) value was 0.33 .

\footnotetext{
Assiut Journal For Sport Science Arts
} 
organizational culture and innovative abilities, with respect to the number of years of experience at the different sports federations. Significant differences were attributed to those who possess 1 to 10 years of experience, for the Calculated (r) value was 0.74 and the tabulated (r) value was 0.41 . For those with 21 to 30 years of experience, the Calculated (r) value was 0.87 and the tabulated (r) value was 0.42 . In contrast, no significant differences were observed between organizational culture and innovative abilities with regard to people with 11 to 20 or 31 to 40 years of experience.

Conclusion, implications and recommendations

In the light of the review of the literature, the findings of this study - based on statistical analyses have pointed out some salient issues. These may be summarized as follows:

- Sports federations in Qatar enjoy a good organizational culture to a large extent.

- With regard to the organizational abilities of the sports federations, the theme regarding maintenance of agreement and harmony ranked the highest in the participants' responses.

- Sports federations in Qatar largely enjoy good abilities at the level of: fluency, flexibility, authenticity, imagination, internal motivation, problem-solving, risk-taking, self-confidence, positive attitudes, determination and persistence, and development.

- No significant statistical differences were observed between sports federations in Qatar, with respect to organizational abilities.

- Significant statistical differences were observed for between sports federations in Qatar, with respect to innovative abilities.

- Significant statistical differences were observed between the sports federations in Qatar, with respect to innovative abilities, in favor of individual games sports federations.

- A significant correlation coefficient was observed between organizational culture and innovative abilities in favor of swimming, handball, volleyball, and tennis.

- In general, differences were observed between organizational culture and 
innovative abilities, with respect to the type of work at sports federations in Qatar (administrative, technical), in favor of administrators.

Drawing on the analysis of the data and the discussion of the findings, this study concludes with the following four recommendations:

- The need to develop and promote the organizational abilities of sports federations in Qatar

- The importance of organizing training workshops to enhance the ability for problem-solving and development.

- The need to support and consolidate the existing agreement/consistency

between sports federations

It recommended that further research is needed to conduct similar studies that involve all sports federations in Qatar and the region. Utilizing a larger sample would be particularly useful to provide a good representation.

\section{Arabic References:}

1- Iman Saber Abdel-Rahman (2008): organizational culture and its relationship with organizational development for the management of physical activity is the major sports clubs in Alexandria, Master Thesis, Faculty of Physical Education for Girls, Alexandria University.

2- Bilal Syed Hashim (2010): organizational culture and its relationship with some of the innovative capabilities of the Egyptian unions, Master Thesis, Faculty of Physical Education, Assiut University.

3- Samia Mohammed Farid (2006): The impact of organizational culture on the empowerment of workers Egyptian Federation of Volleyball, published research, the scientific journal, Faculty of Physical Education, Assiut University.

4- Sawsan Al-Sheikh (1995): the dimensions of organizational culture in the Islamic administrative jurisprudence, the scientific journal of the Faculty of Commerce, Al-Azhar University for Girls Branch.

5- Just before Secretary (1996): organizational culture disparate organizations performance Empirical Study on educational organizations in the United Kingdom, Ph.D. thesis. Cairo University Faculty of Commerce.

6-Manal Ismail Mohamed (2007): The relationship 
between the innovative capacity of the director and some of the organizational and personal variables, Master Thesis, Faculty of Commerce, University of Assiut.

7-. Yun Seok Choi (2005). Analysis of organizational culture in professional baseball organizations based on the competing values framework. A cross-cultural study. University of New Mexico.

8-. Jaskyte, K. (2005). Organization culture and innovation in nonprofit human service organization. University of Alabama.

9-. Jaskyte, K., \& Dressler, W. (2005). Organizational culture and innovation in non-profit human service organizations.
Administration in Social Work, 29(2), 23-41.

10-. The World Book Dictionary (1991). Chicago World Book In 1991.?????? Something missing 11. Valadares, K.J. (2005). Mission, margin and organizational ethics: The contribution of a service-based organizational culture towards enhancing the operational success of health care institutions and its effect on charity care. PhD. Thesis, Saint Louis University, Missouri, pp. 0193.

12. Weston la (1992). Basse; culture in conext ; England duke university press 2nd Edition 